\title{
The Mechanical Properties and Wear Resistance of HVOF Sprayed WC-Co Coatings
}

\author{
Y.Y. ÖZBEK*, N. CANIKOĞLU AND M. İPEK \\ Sakarya University, Metallurgical and Materials Engineering Department, Esentepe Campus, 54187, Turkey \\ In this work, the Woka 5810 powders ( $88 \%$ tungsten carbide- $12 \%$ cobalt) were used to produce coating by \\ high velocity oxy-fuel spraying. WC-Co is widely used as a tribological coating material providing a combination \\ of high toughness, high hardness, and good strength. The treated samples were characterized by using optical \\ micrograph, stereo microscope and scanning electron microscopy, X-ray diffractometry, and microhardness tests. \\ Also the wear performance of the coatings was investigated. The results indicated that the coating shows slight \\ higher microhardness and better abrasive wear resistance than the conventional counterpart. The friction coefficient \\ of coating was low. The scanning electron microscopy and energy dispersive spectroscopy analyses were applied to \\ worn surfaces.
}

DOI: 10.12693/APhysPolA.129.600

PACS/topics: 81.15.Rs

\section{Introduction}

Chemical, petroleum and petrochemical industries demand increased productivity, while in the presence of an aggressive environment, however, production equipment components are generally subjected to thermal cycling, abrasion, erosion, and corrosion [1-3]. The use of protective coatings produced by common surface coating processes such as thermal spray, physical vapor deposition, chemical vapor deposition, and electrolytic hard-chromium processes, among others is highly recommended to avoid material degradation. During the last 20 years, many carbide compositions have been successfully deposited using coating process such as high velocity oxy-fuel (HVOF) thermal spray. These materials are now being specified for critical applications for aircraft components such as landing gears. WC-Co cermet surface coatings are commonly used to enhance the high hardness, wear resistance, thermal stability, and corrosion resistance of many types of engineering components, deposited via air plasma (APS) and HVOF spraying. It has been well established that thermally sprayed WC-Co coatings can exhibit complex, multiphase microstructures, with a significantly lower volume fraction of primary carbide than that of their starting powders [4-7]. The degree of decomposition of the powders during spraying, resulting from these complex microstructures, depends primarily upon two factors, the time-temperature history of the particle and the particle characteristics such as size, porosity, and WC grain size within the particle. Decomposition occurs due to high temperatures and low velocities and the use of small carbide grain sizes within the powder particles, all of which promote carbide dissolution in the molten matrix and

*corresponding author; e-mail: yyarali@sakarya.edu.tr subsequent decarburization. However, while decomposition has been reported to affect wear behavior, low temperature spraying has, in some cases, shown to produce coatings with poorer adhesion between the splats, again resulting in high rates of wear [5-9]. Steel allows the weldability of cemented carbides so it is recommended to join cemented carbide towards steel therefore; studies have been made to reveal the thermal stability and the reaction products of tungsten carbide and steel [10].

In the present research, the $\mathrm{WC}-12 \mathrm{Co}$ coating were produced by an HVOF spray system and the dry sliding wear tests of the coatings were conducted against WC ball. The effects of the different wear rate were investigated.

\section{Experimental procedure}

The feedstock powders were agglomerated and sintered WC-12Co (88wt\%WC-12wt\%Co) powder, and provided by Sulzer-Metco and named Woka 5810. Nominal particle size of using powders is in a range of -63 to $+11 \mu \mathrm{m}$. The powders were sprayed using a high velocity oxyfuel thermal spray process with a JP-5000 gun, with the parameters indicated in Table I. The substrate used for preparing coatings was rectangular stainless steel. In the experiments, there were used different gas mixtures $\left(\mathrm{H}_{2}-\mathrm{O}_{2}\right)$ in HVOF treatment. The passes numbers were selected for 16 and 20. After coating treatment, the coating structure was investigated by different analyses method. Microstructural observations of the coatings (cross-section and surface) were performed using stereo-optic microscope and scanning electron microscopy (SEM)-energy dispersive spectroscopy (EDS) analyses. Microhardness measurements were done on the coating with a microhardness indenter at a load of $300 \mathrm{~g}$ and a dwell time of $15 \mathrm{~s}$.

Friction and wear behaviors are investigated by using the reciprocating slide tester by CSM test machine. Wear tests were conducted in a linear wear test machine with in 
TABLE I

The parameters of HVOF.

\begin{tabular}{c|c|c|c}
\hline \hline $\begin{array}{c}\text { Sample } \\
\text { No. }\end{array}$ & $\begin{array}{c}\text { Distance } \\
{[\mathrm{cm}]}\end{array}$ & $\begin{array}{c}\text { Gas mixture } \\
\left(\mathrm{H}_{2}-\mathrm{O}_{2}\right)\end{array}$ & $\begin{array}{c}\text { Number } \\
\text { of passes }\end{array}$ \\
\hline 1 & 20 & $2-1$ & 16 \\
2 & 20 & $1-1$ & 20 \\
3 & 30 & $2-1$ & 16 \\
4 & 30 & $1-1$ & 20 \\
5 & 20 & $2-1$ & 20
\end{tabular}

reciprocating sliding mode with a $0.15 \mathrm{~m} / \mathrm{s}$ and constant sliding speed under $5 \mathrm{~N}$ loads for $300 \mathrm{~m}$ sliding distance. WC ball with $6 \mathrm{~mm}$ diameter was utilized as counterpart. The friction force was continuously recorded by sensors at the test block so that the coefficient of friction can be calculated with respect to normal force.

All tests were accomplished at room temperature $\left(23^{\circ} \mathrm{C} \pm 3{ }^{\circ} \mathrm{C}\right)$ and in controlled humidity between 20 and $25 \%$. Before the wear test, the surfaces are polished by alumina suspension. Sliding wear tests are carried out at $25^{\circ} \mathrm{C}$. Wear traces are investigated by SEM and EDS. The worn surface was investigated by SEM-EDS.

\section{Results and discussion}

Firstly, the coating surface was investigated by stereo microscope. Figure 1 shows the upper of coating surface structures. All samples have similar surface appearance which has characteristically HVOF structure. However, the gas mixture ratio $\left(\mathrm{H}_{2} / \mathrm{O}_{2}\right)$ and distance and numerous passes made change in surface appearance and morphology.

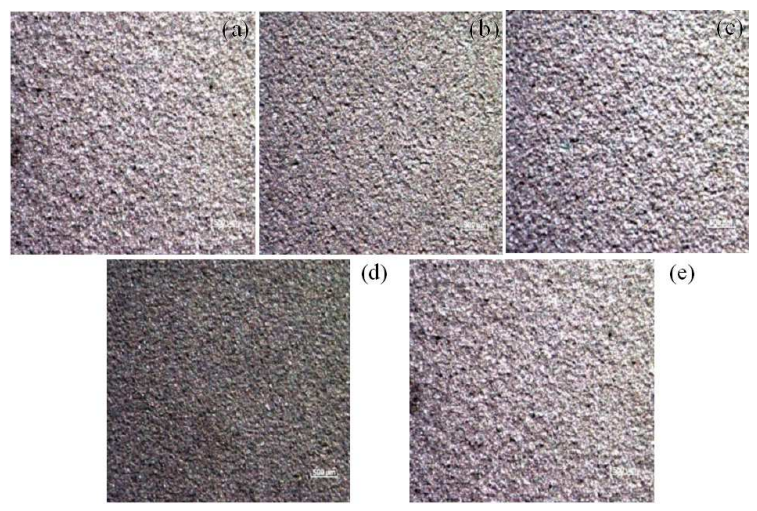

Fig. 1. The stereo microscope images of (a) sample 1, (b) sample 2, (c) sample 3, (d) sample 4, (e) sample 5.

The optic micrographs of sample 1, 3, and 5 are seen in Fig. 2. The thicknesses of coatings change by process parameters. Especially, the gas mixture ratio affected the coating layer. SEM micrographs (Fig. 3) shows that all coated surfaces have randomly distributed small pores with different sizes and lamellar structure which is characteristic for these kinds of coatings [5-8].

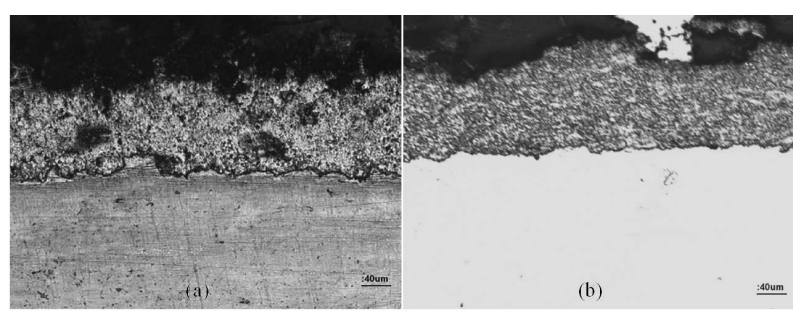

Fig. 2. The optic micrograph of (a) sample 3 and (b) sample 5 .

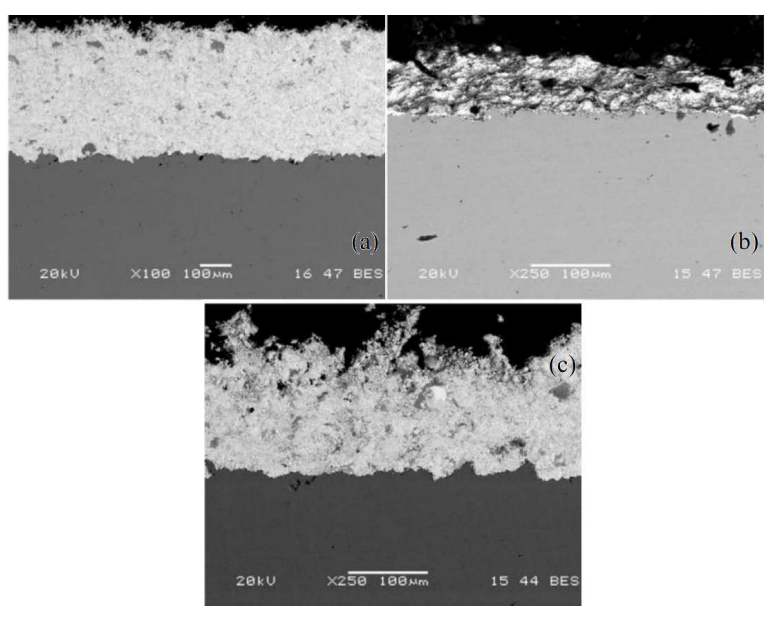

Fig. 3. SEM micrographs of (a) sample 1, (b) sample 2, (c) sample 3 .

All coated samples have the same phases, $\mathrm{WC}, \mathrm{W}_{2} \mathrm{C}$, and Co phases, as seen in Fig. 4. The presence of Co peaks has been attributed to amorphous or nanostructured Co produced by splat quenching $[3,4]$. The proportion of $\mathrm{WC}$ transformed to $\mathrm{W}_{2} \mathrm{C}$ phases was higher for the microstructured coating compared with the nearnanostructured coating [5]. The process parameters affected the microhardness values of sample surface. Microhardness values of the coated surfaces are shown in Fig. 5 with process parameters. Process parameters significantly affect hardness values and the highest hardness value is obtained in sample 1 as $1021 \mathrm{HV}$. The important sequence of parameters is oxygen/hydrogen rate $>$ feed rate $>$ spray distance as in open literature $[9,10]$.

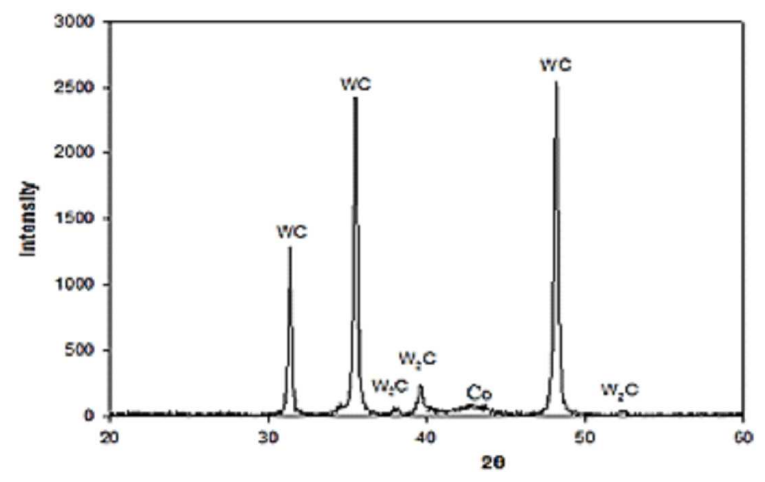

Fig. 4. XRD analyses of coated sample 3. 


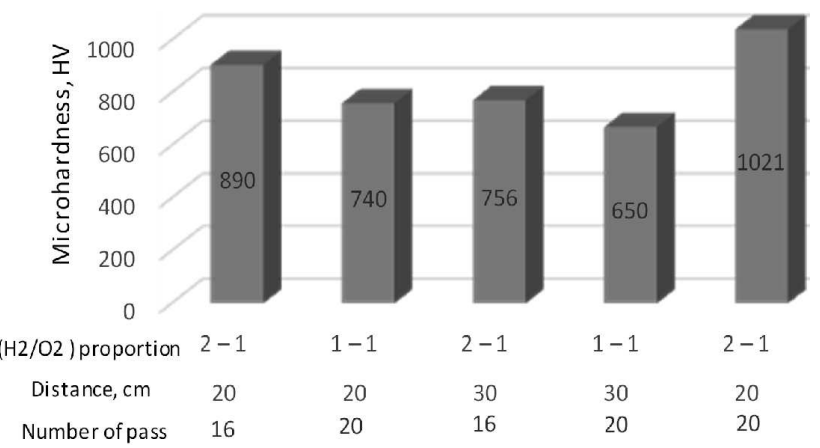

Fig. 5. The microhardness values of coated samples.

Tungsten carbide (WC)-based powders are widely used in high-velocity oxygen fuel (HVOF) spraying to produce dense coatings with high hardness and excellent wear resistance. Wang et al. reported that HVOF sprayed WCbased coating exhibited better antiwear performance as compared with hard chrome plating. Besides initial powder characteristics, the coating process parameters such as feed rate spray distance, type of fuel gas, fuel gas pressure and flow, oxygen gas pressure and flow are important for the performance of the as-sprayed WC-based coating. Some researchers have explored the effect of fuel flow on the performance of HVOF-sprayed WC/Co coatings $[9,10]$. The HVOF $\mathrm{WC}-\mathrm{Co}$ coating is very protective for steel surface.

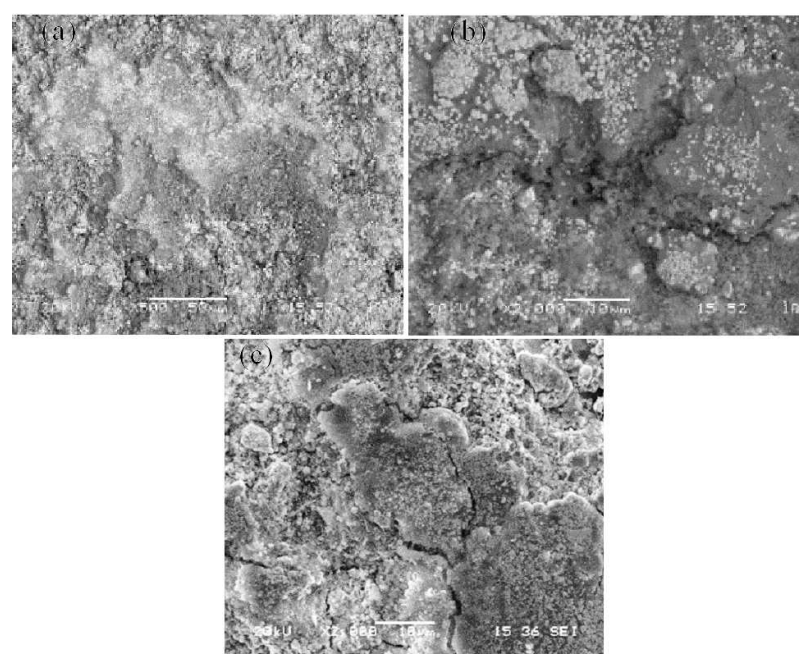

Fig. 6. SEM micrographs of worn surfaces: (a) sample 1, (b) sample 2, (c) sample 3.

Figure 6 shows worn surface after wear test. The abrasive wear and adhesion wear are determined on surface from the SEM micrograph. With the same sliding wear conditions, wear trace of the sample 1 coating is shallow compared with sample 3 which indicates the excellent antiwear performance of HVOF WC-Co coating (as seen in Table II).

The EDS results (Fig. 7 and Table III) show that WC ball worn duration wear test and the wear debris are seen on surface (light gray areas). The friction coefficients of samples are given in Table II. The friction values are changed with process parameters as the other surface properties and the lowest value of friction coefficient is obtained in sample 3 .

TABLE II

The friction coefficient of samples.

\begin{tabular}{c|c}
\hline \hline Sample No. & Friction coefficient \\
\hline 1 & 0.300 \\
2 & 0.385 \\
3 & 0.242 \\
4 & 0.282 \\
5 & 0.279
\end{tabular}

TABLE III

EDS point analysis of sample 4 .

\begin{tabular}{c|c|c|c|c|c|c|c}
\hline \hline \multirow{2}{*}{ [wt\%] } & \multicolumn{7}{|c}{ Points of EDS analysis } \\
\cline { 2 - 8 } & 1 & 2 & 3 & 4 & 5 & 6 & 7 \\
\hline $\mathrm{C}$ & 3.305 & 2.393 & 0.000 & 3.280 & 3.169 & 6.801 & 0.818 \\
$\mathrm{O}$ & 8.230 & 13.460 & 9.627 & 8.024 & 13.589 & 7.759 & 8.595 \\
$\mathrm{Cr}$ & 1.087 & 7.670 & 14.813 & 1.828 & 6.119 & 0.614 & 1.354 \\
$\mathrm{Co}$ & 12.145 & 1.542 & 1.640 & 1.811 & 3.879 & 2.641 & 3.485 \\
$\mathrm{~W}$ & 75.233 & 46.824 & 9.146 & 76.817 & 52.600 & 79.162 & 81.128 \\
$\mathrm{Fe}$ & & 28.111 & 57.165 & 8.240 & 20.644 & 3.023 & 4.621 \\
$\mathrm{Ni}$ & & & 7.610 & & & &
\end{tabular}

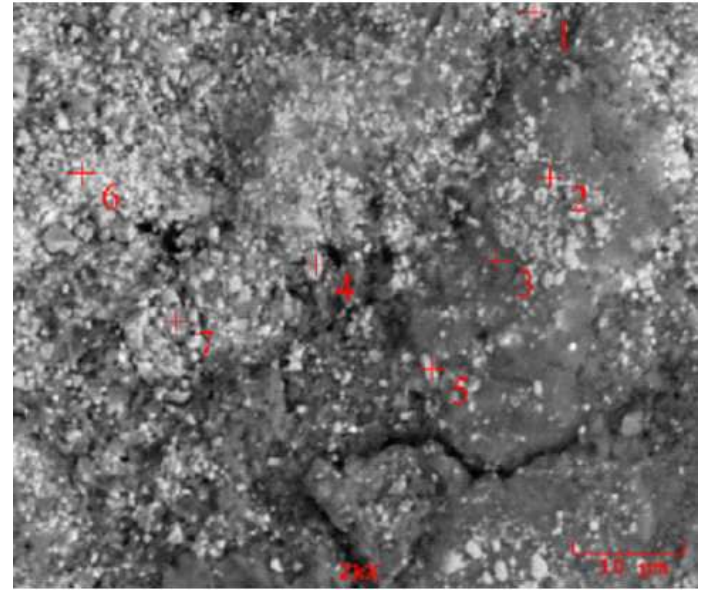

Fig. 7. EDS point analysis of sample 4.

\section{Conclusion}

In this study, there is produced $\mathrm{WC}-\mathrm{Co}$ coating by HVOF using different process parameters and investigated coating and wear properties. The following results are obtained:

1. The process parameters affect surface properties.

2. Mechanical properties of coating surface increase and the maximum hardness is obtained as $1021 \mathrm{HV}$. 
3. The adhesive and abrasive wear are determined on worn surface.

4. The friction coefficient values change with different process parameters.

\section{References}

[1] T.I. Khan, G.C. Saha, L.B. Glenesk, Surf. Eng. 26, 540 (2010).

[2] S. Al-Mutairi, M.S.J. Hashmi, B.S. Yilbas, J. Stokes, Surf. Coat. Technol. 264, 175 (2015).

[3] N. Ma, L. Guo, Z. Cheng, H. Wu, F. Ye, K. Zhang, Appl. Surf. Sci. 320, 364 (2014).

[4] U. Selvadurai, P. Hollingsworth, I. Baumann, B. Hussong, W. Tillmann, S. Rausch, D. Biermann, Surf. Coat. Technol. 268, 30 (2015).
[5] S. Hong, Y. Wu, B. Wang, Y. Zheng, W. Gao, G. Li, Mater. Des. 55, 286 (2014).

[6] T. Sudaprasert, P.H. Shipway, D.G. McCartney, Wear 255, 943 (2003).

[7] W. Fang, T.Y. Cho, J.H. Yoon, K.O. Song, S.K. Hur, S.J. Youn, H.G. Chun, J. Mater. Process. Technol. 209, 3561 (2009).

[8] Q. Wang, J. Xiang, G. Chen, Y. Cheng, X. Zhao, S. Zhang, J. Mater. Process. Technol. 213, 1653 (2013).

[9] A. Mateen, G.C. Saha, T.I. Khan, F.A. Khalid, Surf. Coat. Technol. 206, 1077 (2011).

[10] J.M. Guilemany, S. Dosta, J. Nin, R. Miguel, J. Therm. Spray Technol. 14, 335 (2005). 